\title{
ANÁLISE DA ERODIBILIDADE DE UM CAMBISSOLO POR MEIO DE UM TRANSECTO EM ENCOSTA ÍNGREME DA BACIA HIDROGRÁFICA DO RIO PEQUENO, PARATY - RJ
}

\author{
Rafael Carvalho Santos ${ }^{(a)}$, Leonardo dos Santos Pereira ${ }^{(b)}$, Antonio José Teixeira Guerra ${ }^{(c)}$ \\ (a) Programa de Pós-Graduação em Geografia/Instituto de Geociências, UFRJ, E-mail: rafac.16@ gmail.com \\ (b) Programa de Pós-Graduação em Geografia/Instituto de Geociências, UFRJ, E-mail: leospgeo@ gmail.com \\ (c) Programa de Pós-Graduação em Geografia/Instituto de Geociências, UFRJ, E-mail: antoniotguerra@gmail.com
}

\section{EIXO: SOLOS E PAISAGENS}

\begin{abstract}
Resumo
Ao longo do tempo, as paisagens vêm sendo transformadas pelas atividades humanas, interferindo na dinâmica dos sistemas naturais e, em muitos casos, acarretando em sua instabilidade. Neste sentido, emergem problemas como a erosão dos solos, pondo em risco a conservação desse recurso tão importante e, consequentemente, de suas múltiplas funções. Assim, este trabalho tem como objetivo analisar a erodibilidade de um Cambissolo através do estudo de seus atributos físicos e químicos ao longo de um transecto em encosta íngreme. Nesse estudo foram coletadas amostras na camada superficial do solo e realizadas análises de granulometria, densidade aparente, porosidade total, estabilidade de agregados, matéria orgânica, $\mathrm{pH}$ e fertilidade. Os atributos físicos e químicos do solo, analisados ao longo da encosta, indicaram baixa erodibilidade. Contudo, as terras apresentam fortes restrições às atividades agrícolas ali desenvolvidas, relacionadas à declividade acentuada e a baixa fertilidade natural do solo.
\end{abstract}

Palavras chave: Propridedades do solo, Erosão, Uso da terra.

\section{Introdução}

A crescente ocupação da superfície da Terra e exploração dos recursos naturais tem levado a transformações profundas da paisagem, acarretando na instabilidade dos sistemas e surgimento de consequências, muitas vezes negativas, que afetam a natureza e a sociedade (TRICART, 1977; CUNHA e GUERRA, 2011; PIDWIRNY, 2014). Compreender estes problemas, que são complexos, é tarefa árdua e necessária para a busca de soluções viáveis que visem à conservação ambiental e a justiça social (LEFF, 2012).

A erosão dos solos é um problema ambiental que ocorre em diferentes escalas no tempo-espaço, sendo uma das principais formas de degradação dos solos no mundo. Apesar de a erosão ser um processo geomorfológico natural, responsável pela esculturação do relevo, ao longo do tempo, através da remoção, transporte e deposição de matérias das encostas para áreas mais deprimidas, os processos erosivos vêm 
sendo acelerados por práticas humanas desenvolvidas de maneira inadequada (MORGAN, 2005; FAVISMORTLOCK, 2012; GUERRA et al., 2017).

A intensidade dos processos erosivos vai depender da combinação de alguns fatores controladores, são eles: a erosividade da chuva, a erodibilidade dos solos, as características das encostas, a cobertura vegetal e, também, a ação do homem (MORGAN, 2005; GUERRA, 2016). Devido ao desflorestamento, as queimadas, enfim, o uso e o manejo inadequado do solo, o deixa ainda mais frágil à ação das chuvas, podendo provocar o desprendimento de partículas e o aumento do escoamento superficial nas encostas, acarretando em taxas excessivas de perda de solo. Como consequência da erosão dos solos, surgem problemas ligados a perda da camada superficial do solo, diminuição da fertilidade e produtividade agrícola, perda de área agricultável, aumento dos custos de produção, entre outros danos (LEPSCH, 2011; GUERRA, 2014; OSMAN, 2014).

A erodibilidade do solo, de maneira geral, refere-se ao grau de resistência do solo à erosão, onde suas propriedades físicas e características químicas são importantes indicadores. A textura, a estabilidade dos agregados, a densidade aparente, a porosidade e a matéria orgânica do solo são propriedades que vão influenciar na resistência a desagregação e remoção de partículas do solo pela ação da chuva e/ou do escoamento superficial, assim como influem no processo de infiltração, na permeabilidade e no armazenamento de água no solo (MORGAN, 2005; GUERRA, 2013; BERTONI e LOMBARDI NETO, 2014).

Tal como os processos erosivos, a erodibilidade do solo varia no espaço e no tempo de acordo com a dinâmica pedológica e sua relação com o ambiente (WANG et al., 2013). Sabe-se que o uso da terra de forma inadequada, especialmente por atividades agropecuárias, pode provocar alterações diretas e/ou indiretas em algumas propriedades do solo, modificando sua estrutura, compactando-o e, consequentemente, o deixando mais erodível (MAFRA, 2012; GUERRA, 2013; KEESSTRA et al., 2016). Nesse sentido, o objetivo deste trabalho é analisar a erodibilidade de um Cambissolo através do estudo de seus atributos físicos e químicos, ao longo de um transecto, em encosta íngreme, sob diferentes usos da terra.

\section{Materiais e métodos}

A área de estudo está inserida na bacia hidrográfica do Rio Pequeno, localizada no município de Paraty RJ (Figura 1). A bacia é marcada por relevo movimentado, resultado do amplo desnível topográfico entre a Baía da Ilha Grande e a Serra da Bocaina, apresentando cotas altimétricas que vão de, aproximadamente, 


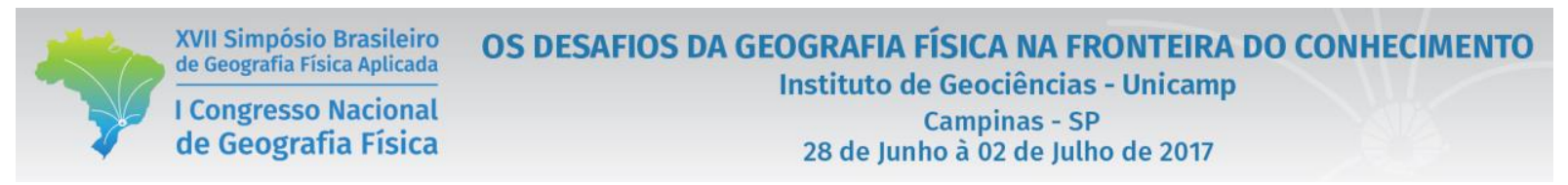

0 a 1840 metros. O clima pode ser definido como tropical úmido, ocorrendo variações espaciais das chuvas e temperaturas. A pluviosidade média anual da estação pluviométrica São Roque, a mais próxima da área, foi de $2.296 \mathrm{~mm}$ no período entre 1969 - 2011 (ANA, 2016). A elevada pluviosidade é decorrente da influência marinha e do relevo que constitui uma barreira natural para as massas de ar, favorecendo a ocorrência de chuvas orográficas (BRASIL, 2002; RIO DE JANEIRO, 2011).

\section{Mapa de localização da Bacia Hidrográfica do Rio Pequeno, Paraty - RJ}
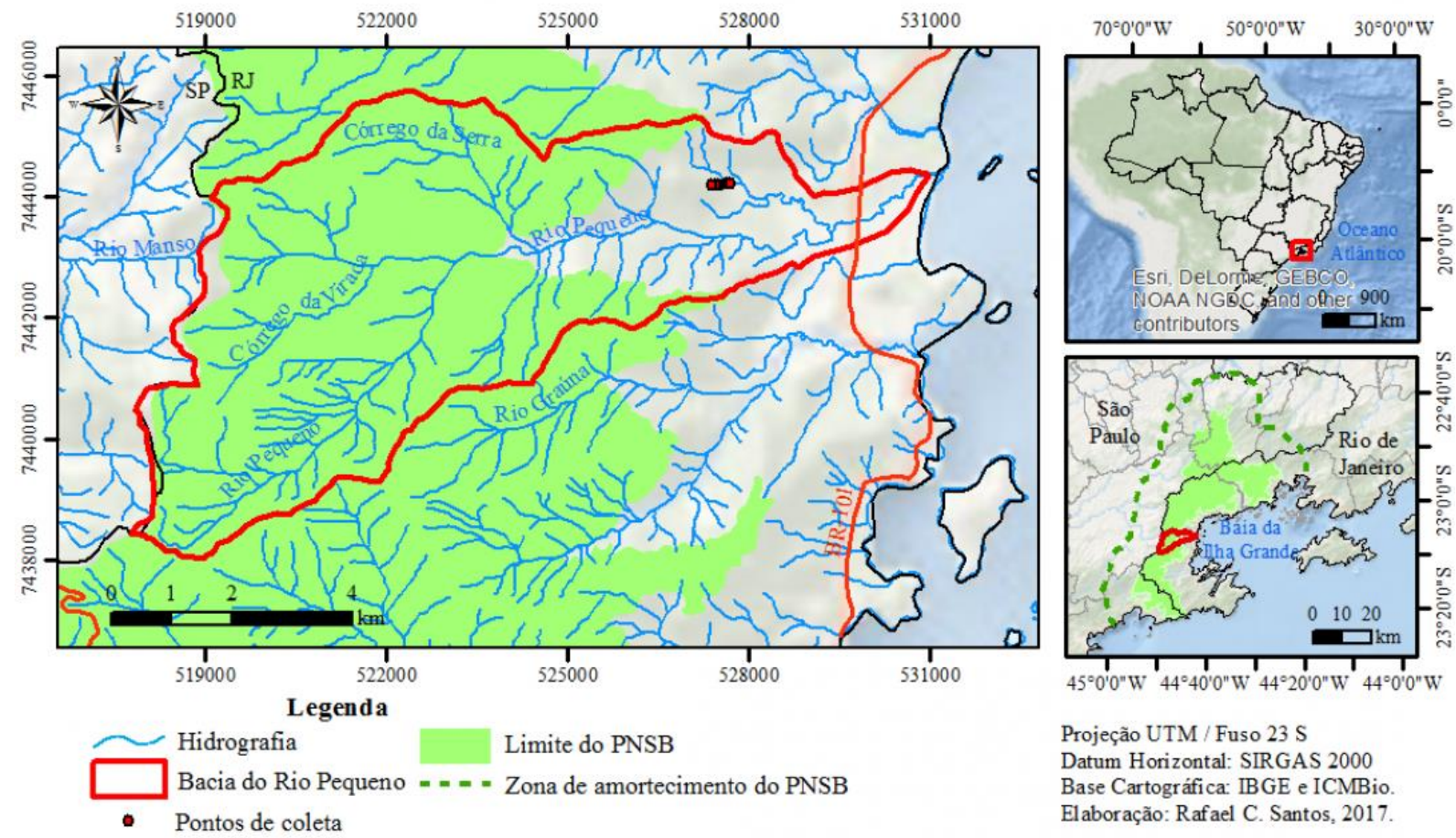

Figura 1 - Localização da bacia hidrográfica do Rio Pequeno, Paraty - RJ.

As características ambientais da bacia, sobretudo, o predomínio de relevo escarpado, altos índices pluviométricos e rochas graníticas, contribuem para a ocorrência predominante dos Cambissolos. Na encosta em estudo ocorre o Cambissolo Háplico Distrófico, que de maneira geral, é pouco evoluído, raso a pouco profundo, com presença de fragmentos de rochas, argila de baixa atividade e fertilidade natural baixa (BRASIL, 2002; CARVALHO FILHO et al., 2003).

A área abriga ampla diversidade de espécies da fauna e flora características da Mata Atlântica, protegidos pelo Parque Nacional da Serra da Bocaina - PNSB. Apesar disso, ainda se observam pressões das atividades humanas sobre o PNSB e sua zona de amortecimento (BRASIL, 2002; GUERRA et al., 2013). Segundo o Sistema Nacional de Unidade de Conservação - SNUC, a zona de amortecimento abarca o entorno da UC e também deve estar submetida ao plano de manejo, buscando através de normas e restrições específicas sobre as atividades humanas, diminuir os danos ambientais sobre a UC (BRASIL, 2000). 


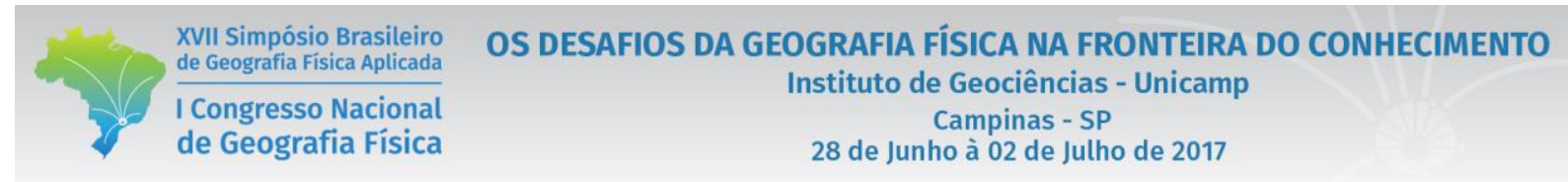

Nesse sentido, foi selecionada uma encosta no baixo curso da bacia do Rio Pequeno para a realização do estudo, onde se fez um transecto da média até a baixa encosta (Figura 2). O trasecto possui, aproximadamente, 300 metros de comprimento com declividade média de $25^{\circ}$, a forma da encosta é retilínea em perfil e convexa em planta. $\mathrm{O}$ uso da terra se divide em três classes: floresta, cultivo temporário (madioca) recém-plantado e cultivo permanente (coqueiro) plantado a mais de 10 anos (Figura $3)$.

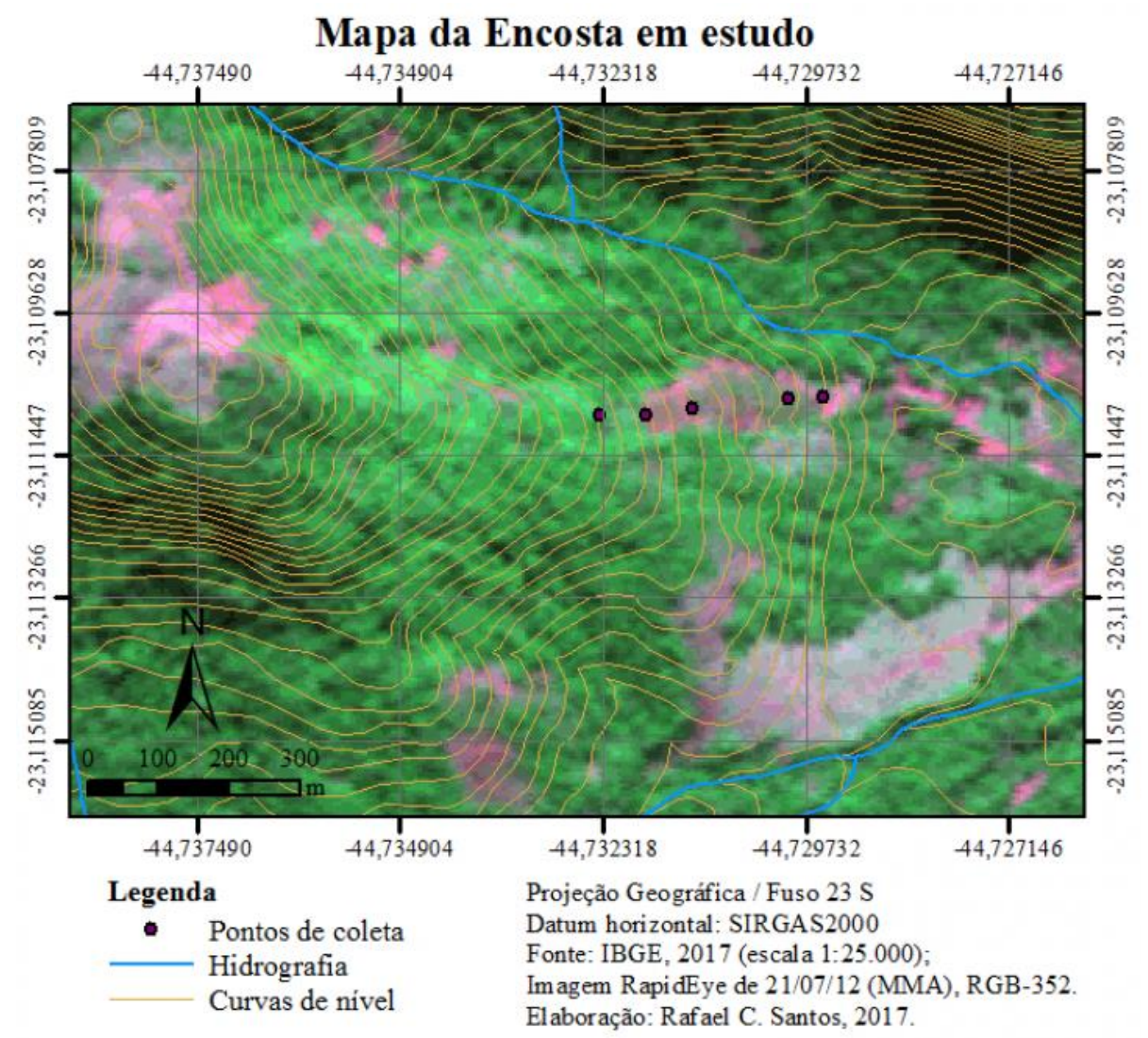

Figura 2 - Curvas de nível e uso da terra da encosta em estudo, Paraty - RJ.

A fim de inferir sobre a erodibilidade, foram coletadas amostras volumétricas, deformadas e indeformadas da camada superficial do solo, em duas profundidades $(0-10$ e 10-20 cm), onde se observa maior influência das atividades humanas sobre algumas propriedades do solo, fundamentais para sua resistência à erosão (ARAUJO et al., 2007; BRADY e WEIL, 2008; PEREIRA e THOMAZ, 2015).

Posteriormente, no Laboratório de Geomorfologia da UFRJ, foram realizadas análises da granulometria (método da pipeta), densidade aparente (método do anel volumétrico), densidade de partículas (método do balão volumétrico com álcool), porosidade total, carbono orgânico (óxidação da matéria orgânica via úmida com dicromato de potássio em meio sulfúrico) e pH (eletrodo combinado imerso em suspensão solo:água, 1:2,5), ambos os procedimentos baseados nas orientações da EMBRAPA (1997). 


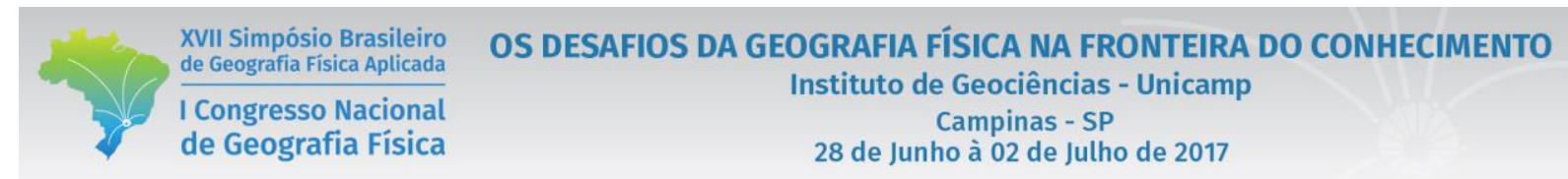

A estabilidade dos agregados em água foi feita seguindo o método proposto por Yoder (1936) modificado por Castro Filho et al. (1998), onde as amostra indeformadas foram homogeneizadas, utilizando a peneira de $4 \mathrm{~mm}$, umedecidas e levadas ao equipamento Yoder, sendo submetidas a oscilações verticais na água durante 15 minutos com frequência de 32 rotações por minuto. Os agregados retidos em cada peneira foram secos na estufa a $105^{\circ} \mathrm{C}$ por 24 horas (EMBRAPA, 1997). Após pesados, os resultados foram utilizados nos cálculos do Diâmetro Médio Ponderado - DMP, Diâmetro Médio Geométrico - DMG e Índice de Estabilidade dos Agregados - IEA utilizando as equações de Kemper e Rosenau (1986) modificadas por Castro Filho et al. (2002), onde:

- $\operatorname{DMP}(\mathrm{mm})=\sum$ (xi.wi), em que wi = proporção $(\%)$ de cada classe em relação ao total; e xi= diâmetro médio das classes, expresso em mm;

- $\quad \operatorname{DMG}(\mathrm{mm})=\exp \left(\sum\right.$ wilnxi/ $/$ wi $)$, em que wi = proporção $(\%)$ de cada classe em relação ao total; e xi= diâmetro médio das classes, expresso em mm;

- $\operatorname{IEA}(\%)=(($ peso total dos agregados - peso dos agregados $<0,25 \mathrm{~mm}) /$ peso da amostra $) \times 100$.

Todas as análises laboratoriais foram feitas em tríplicata, calculando-se a média, o desvio padrão e o coeficiente de variação. Também, foram realizadas análises químicas de rotina para fins de fertilidade do solo na EMBRAPA Solos, através de duas amostras deformadas (floresta e cultivo permanente), na profundidade de $0-10 \mathrm{~cm}$.

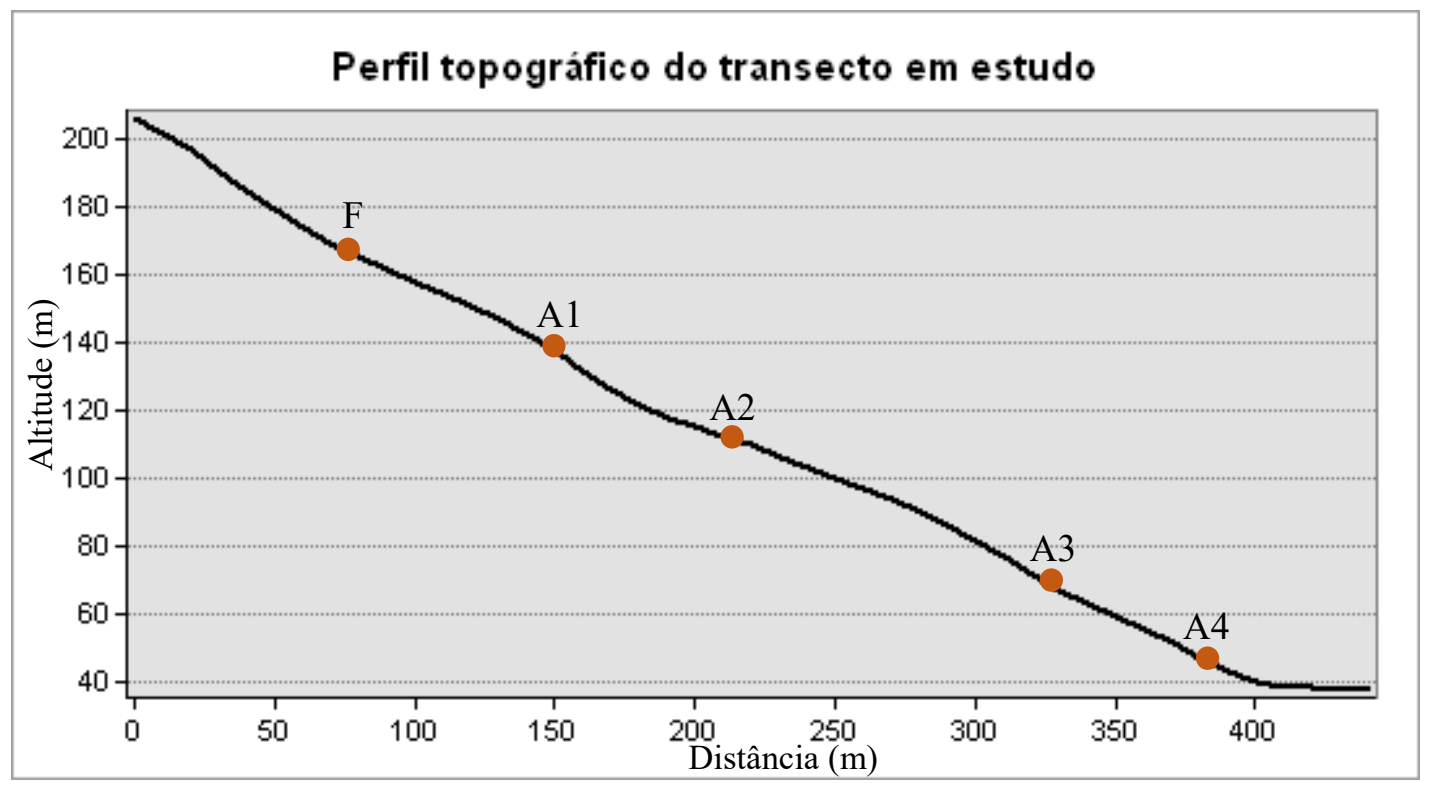

Figura 3 - Perfil topográfico do transecto em estudo, Paraty - RJ. Elaborado a partir da folha topográfica SF-23-Z-CI-2 de Parati, escala 1:50.000. F - floresta; A1 - cultivo temporário; A2, A3 e A4 - cultivo permanente. 


\section{OS DESAFIOS DA GEOGRAFIA FÍSICA NA FRONTEIRA DO CONHECIMENTO \\ Instituto de Geociências - Unicamp \\ Campinas - SP \\ 28 de Junho à 02 de Julho de 2017}

\section{Resultados e discussão}

A textura é uma das propriedades do solo que afeta sua erodibilidade, pois as frações granulométricas areia fina e silte são mais facilmente erodidas, enquanto a areia grossa e a argila são mais resistentes aos processos erosivos (MORGAN, 2005; GUERRA, 2013; OSMAN, 2014). As amostras de Cambissolo demonstram que há um equilíbrio na distribuição do tamanho das partículas do solo, predominando a classe textural franco (Tabela I). A fração areia grossa mostrou-se presente em quantidades superiores à areia fina em todas as amostras, correspondendo a mais de $74 \%$ do total de areia, proporcionando maior porosidade e, apesar de apresentar baixa agregação, possui maior resistência à remoção pelas gotas de chuva e escoamento superficial devido a sua massa. No ponto $\mathrm{F}$ ocorre a maior concentração de areia grossa e a menor de argila, na profundidade de $0-10 \mathrm{~cm}$, talvez devido ao processo de elutriação que provoca a remoção das partículas mais finas do topo do solo pelo escoamento superficial da água em longo prazo.

Tabela I - Valores médios da análise granulométrica de um Cambissolo sob diferentes usos em Paraty - RJ.

\begin{tabular}{|c|c|c|c|c|c|c|c|}
\hline \multirow{2}{*}{$\begin{array}{l}\text { Ponto de } \\
\text { coleta }\end{array}$} & \multirow{2}{*}{$\begin{array}{l}\text { Profun- } \\
\text { didade } \\
\text { (cm) }\end{array}$} & \multicolumn{5}{|c|}{ Granulometria (\%) } & \multirow[b]{2}{*}{ Classe textural } \\
\hline & & $\begin{array}{c}\text { Areia } \\
\text { Grossa }\end{array}$ & $\begin{array}{c}\text { Areia } \\
\text { Fina }\end{array}$ & Silte & Argila & $\begin{array}{c}\text { Areia fina + } \\
\text { Silte }\end{array}$ & \\
\hline \multirow{2}{*}{$\mathrm{F}$} & $0-10$ & 58,38 & 7,76 & 24,17 & 9,70 & 31,93 & Franco arenoso \\
\hline & $10-20$ & 37,99 & 11,45 & 33,39 & 17,17 & 44,84 & Franco \\
\hline \multirow{2}{*}{ A1 } & $0-10$ & 42,07 & 9,66 & 34,23 & 14,04 & 43,89 & Franco \\
\hline & $10-20$ & 40,82 & 10,18 & 30,18 & 18,82 & 40,36 & Franco \\
\hline \multirow{2}{*}{ A2 } & $0-10$ & 32,81 & 10,89 & 33,14 & 23,16 & 44,03 & Franco \\
\hline & $10-20$ & 33,48 & 11,80 & 34,89 & 19,83 & 46,69 & Franco \\
\hline \multirow{2}{*}{ A3 } & $0-10$ & 35,52 & 10,78 & 31,91 & 21,78 & 42,69 & Franco \\
\hline & $10-20$ & 32,03 & 9,55 & 22,84 & 35,59 & 32,39 & Franco argiloso \\
\hline \multirow{2}{*}{ A4 } & $0-10$ & 44,39 & 10,45 & 25,77 & 19,39 & 36,22 & Franco arenoso \\
\hline & $10-20$ & 39,59 & 11,46 & 28,78 & 20,17 & 40,24 & Franco \\
\hline \multicolumn{2}{|c|}{ Média } & 39,71 & 10,40 & 29,93 & 19,97 & 40,33 & \\
\hline \multicolumn{2}{|c|}{ Desvio padrão } & 7,77 & 1,20 & 4,36 & 6,73 & 5,20 & \\
\hline \multicolumn{2}{|c|}{ CV (\%) } & 19,57 & 11,50 & 14,58 & 33,71 & 12,89 & \\
\hline
\end{tabular}

Os teores de argila mantiveram-se abaixo de $24 \%$, com exceção do ponto A3 $(10-20 \mathrm{~cm})$ que possui mais de $35 \%$ de argila e sua textura foi definida como franco argiloso, podendo ser explicado por ser uma camada de transição entre os horizontes A e B. No que se refere aos teores de areia fina + silte, a maioria dos pontos apresentaram valores entre $40 \%$ e $47 \%$, cabendo observar os teores de argila e matéria orgânica - MO, que vão contribuir para a agregação do solo, assim como a cobertura vegetal que oferece proteção ao solo contra a chuva e o escoamento superficial. Ao análisar as variações texturais ao longo da 
encosta se nota que existe um ligeiro aumento das frações mais finas do ponto $\mathrm{F}$ ao $\mathrm{A} 3$, enquanto que no ponto A4 há um incremento de areia grossa.

Os resultados da análise de densidade aparente - Da indicaram média compactação dos solos e porosidade total em torno de 50\% (Figura 4), em decorrência da textura, teor de MO e da presença de fragmentos minerais, favorecendo a infiltração de água no solo (BRADY e WEIL, 2008; PEREIRA et al., 2016). Notou-se que os pontos F, A1 e A2 apresentaram Da inferior a 1,2 g/ $\mathrm{cm}^{3}$ e Pt superior a 50\%, enquanto que os pontos A3 e A4 estão um pouco mais compactados com Da superior a $1,3 \mathrm{~g} / \mathrm{cm}^{3}$ e $\mathrm{Pt}$ abaixo de $48 \%$.

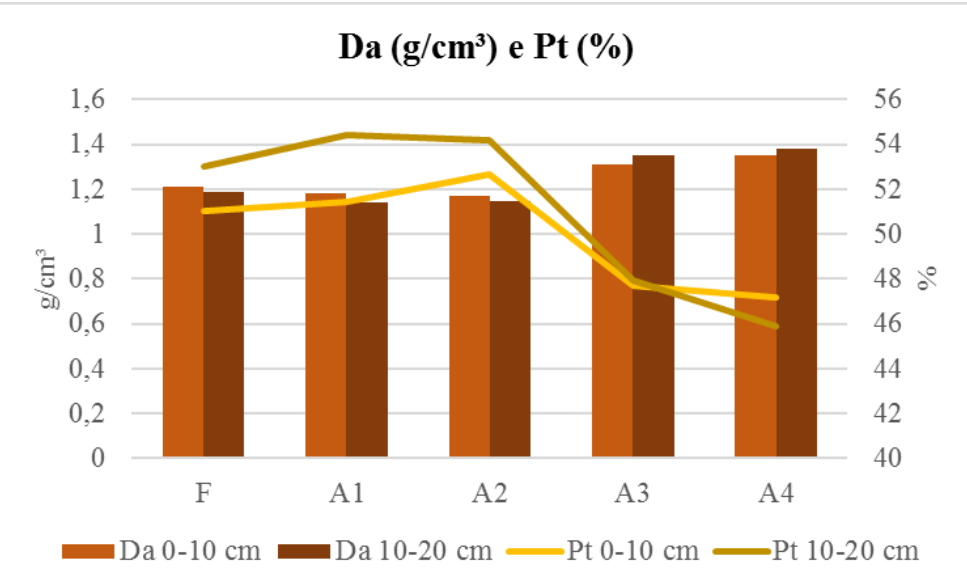

Figura 4 - Valores médios para Densidade aparente - Da e Porosidade total - Pt de um Cambissolo sob diferentes usos em Paraty - RJ.

$\mathrm{O}$ carbono orgânico - $\mathrm{CO}$ e, consequentemente, a MO diminuíram com a profundidade em todos os pontos (Tabela II). Contudo, a maioria das amostras apresentaram teores de $\mathrm{CO}$ e $\mathrm{MO}$, respectivamente, superiores a 2,0\% e 3,5\%, indicando menor suscetibilidade à erosão (MORGAN, 2005; GUERRA, 2016). Apenas os pontos A3 e A4, na profundidade de $10-20 \mathrm{~cm}$, têm valores críticos que podem conferir maior erodibilidade ao solo, tendo em vista a importância desta propriedade para aumentar a estabilidade dos agregados e, consequentemente, a capacidade de infiltração e resistência do solo aos processos erosivos superficiais (MAFRA, 2012; XU et al., 2016).

$\mathrm{O}$ pH indica que o Cambissolo é fortemente ácido (Tabela II), com resultados que vão de 4,9 a 3,6, característica comum em regiões úmidas, devido ao acelerado intemperismo químico sobre os minerais primários, formando minerais secundários e perdendo as bases trocáveis através da lixiviação (BRADY e WEIL, 2008; LEPSCH, 2011; OSMAN, 2014). Ao comparar os atributos químicos (relacionados a fertilidade) do solo (Tabela III) na camada superficial sob cobertura vegetal de floresta (F) e cultivo permanente (A), observa-se que ambos possuem baixa fertilidade, entretanto, o ponto $\mathrm{F}$ apresentou maior soma de bases - S, Capacidade de Troca de Cátions efetiva a pH 7,0 - T e saturação por bases - V\% do 


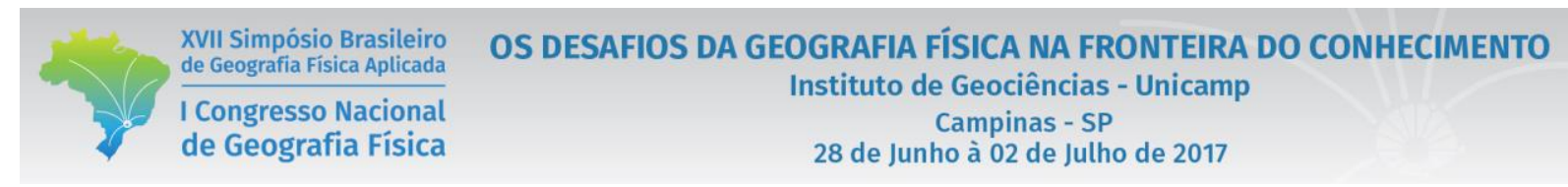

que o ponto A. Além disso, a concentração de $\mathrm{Al}$ aumentou no ponto $\mathrm{A}$ em relação ao $\mathrm{F}$. Logo, as mudanças na cobertura vegetal têm influenciado no aporte de MO do solo, importante para o aumento das ligações e reações químicas que ocorrem no solo, o que associado aos altos índices pluviométricos e à declividade, favorecem o processo de lixiviação e erosão, que podem dificultar o crescimento das plantas (OSMAN, 2014).

Tabela II - Valores médios de Carbono Orgânico - CO, Matéria Orgânica - MO e pH de um Cambissolo sob diferentes usos em Paraty - RJ.

\begin{tabular}{ccccccr}
\hline \multirow{2}{*}{$\begin{array}{c}\text { Ponto } \\
\text { de coleta }\end{array}$} & \multicolumn{2}{c}{$\mathbf{C O}(\boldsymbol{\%})$} & \multicolumn{2}{c}{ MO $(\boldsymbol{\%})$} & \multicolumn{2}{c}{$\mathbf{p H}$} \\
\cline { 2 - 8 } & $0-10 \mathrm{~cm}$ & $10-20 \mathrm{~cm}$ & $0-10 \mathrm{~cm}$ & $10-20 \mathrm{~cm}$ & $0-10 \mathrm{~cm}$ & $10-20 \mathrm{~cm}$ \\
\hline F & 4,33 & 2,47 & 7,47 & 4,25 & 4,4 & 4,0 \\
A1 & 4,53 & 3,78 & 7,82 & 6,51 & 4,7 & 4,6 \\
A2 & 3,96 & 2,46 & 6,82 & 4,23 & 4 & 3,6 \\
A3 & 2,62 & 1,24 & 4,52 & 2,14 & 4,9 & 4,6 \\
A4 & 2,65 & 1,43 & 4,57 & 2,47 & 4,7 & 3,8 \\
\hline Média & 2,95 & 5,08 & 4,32 & \\
Desvio padrão & 1,16 & 1,99 & & 0,45 & \\
CV (\%) & 39,20 & 39,22 & & 10,43 \\
\hline
\end{tabular}

A estabilidade dos agregados em água é uma das propriedades mais importantes para se avaliar a erodibilidade de um solo, pois favorece o comportamento hidrológico do topo do solo e dificulta a ruptura dos agregados e, consequente, a formação de crosta na superfície do mesmo (DE PLOEY e POESEN, 1985; GUERRA, 2013; WANG et al., 2013). As amostras analisadas demonstram que o Cambissolo possui boa estabilidade de agregados em água, com médias de DMP, DMG e IEA, respectivamente, de 2,72 mm, 2,53 mm e 96,90\% (Figura 5). Os parâmetros da estabilidade dos agregados diminuíram ao longo da encosta do ponto $\mathrm{F}$ ao A3 e aumentou no ponto A4. Acredita-se que a classe textural franco arenoso do A4 tenha influenciado nesse resultado.

Tabela III - Atributos químicos de um Cambissolo sob diferentes usos em Paraty - RJ.

\begin{tabular}{|c|c|c|c|c|c|c|c|c|c|c|c|c|}
\hline \multirow{2}{*}{ Ponto } & \multirow{2}{*}{$\begin{array}{c}\text { Profun- } \\
\text { didade } \\
\text { (cm) }\end{array}$} & \multirow{2}{*}{$\begin{array}{c}\text { pH } \\
\text { H2O }\end{array}$} & $\mathbf{P}$ & $\mathbf{K}$ & $\mathbf{N a}$ & $\mathrm{Ca}$ & Mg & Al & \multirow{2}{*}{$\begin{array}{l}\text { Acidez Total } \\
\mathrm{cmolc} / \mathrm{dm}^{3}\end{array}$} & \multirow[t]{2}{*}{$\mathbf{S}$} & \multirow[t]{2}{*}{$\mathbf{T}$} & \multirow{2}{*}{$\frac{\mathbf{V}}{(\%)}$} \\
\hline & & & & $\mathrm{mg} / \mathrm{dm}^{3}$ & & & & & & & & \\
\hline F & $0-10$ & 4,6 & 2,49 & 132,60 & 6,90 & 2,8 & 1,6 & 0,5 & 10,23 & 4,77 & 15,00 & 31,80 \\
\hline A & $0-10$ & 4,3 & 2,63 & 50,70 & 6,90 & 0,7 & 0,5 & 1,7 & 11,39 & 1,36 & 12,75 & 10,67 \\
\hline
\end{tabular}

A cobertura vegetal e o uso do solo ao longo do transecto em estudo, como citado anteriormente, interferem na resposta dos solos à ação das chuvas. As terras nessa área (Figura 6) apresentam forte restrição relacionada à declividade acentuada e a baixa fertilidade natural do solo, sendo os cultivos viabilizados, principalmente, pela presença de horizonte superficial rico em MO. Nesse sentido, as platações se expandem em direção à mata, com utilização de técnicas rudimentares (queimadas e coivara), 


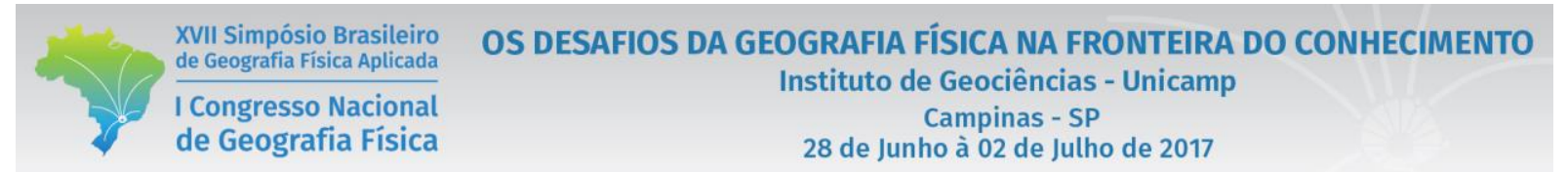

deixando o solo exposto para o cultivo e suscetível à erosão pelo escoamento superficial, mesmo apresentando atributos físicos e químicos que lhe confere baixa erodibilidade.

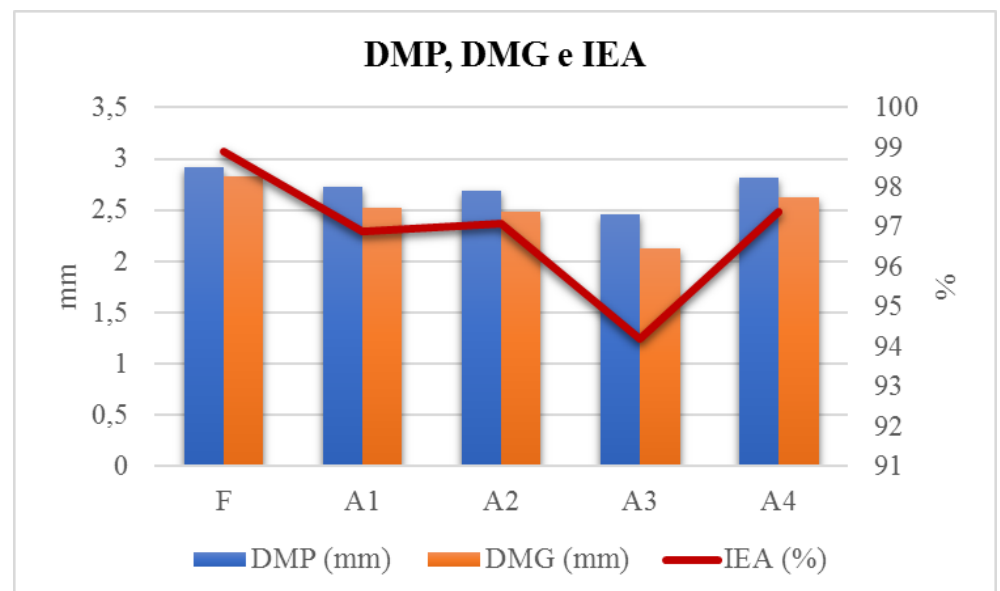

Figura 5 - Diâmetro Médio Ponderado - DMP, Diâmetro Médio Geométrico - DMG e Índice de Estabilidade dos Agregados - IEA de um Cambissolo, na profundidade de 0-10 cm, sob diferentes usos em Paraty - RJ.

Pereira et al. (2016) destacam a ocorrência de processos erosivos superficiais em terrenos de baixa declividade $\left(4^{\circ}\right)$ com horizonte B exposto, através de estudo com parcela de erosão, realizado no litoral norte paulista. O comportamento hidrológico pode ser prejudicado em solos sem cobertura vegetal, e também em solos cujo horizonte $\mathrm{A}$ foi perdido, caracterizando a presença de uma área degradada, pois os solos possuem baixo teor de matéria orgânica, dificultando o crescimento das plantas em curto prazo, e baixa capacidade de drenagem, por apresentar baixa porosidade para absorção da água das chuvas, podendo acelerar a ocorrência do escoamento superficial (PEREIRA et al., 2016; ILEK et al., 2017).

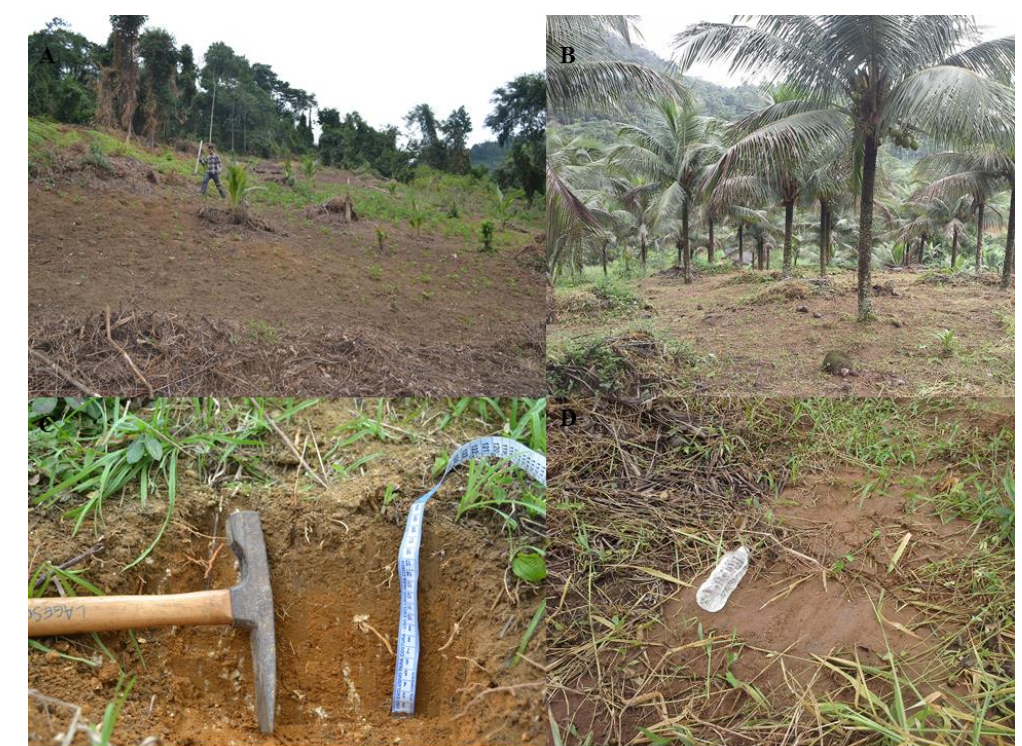

Figura 6 - Área com cultivo temporário (A), cultivo permanente de coqueiro (B), perfil de 0-20 cm no ponto A4 (C) e erosão laminar no cultivo permanente (D), em Paraty - RJ. 
O principal tipo de erosão identificado na encosta foi a laminar (Figura 6D). Lepsch (2011) afirma que a erosão laminar é a responsável pela maior taxa de perda de solos no Brasil, destacando sua atuação lenta e insidiosa. Muller-Nedebock e Chaplot (2015) apontam a erosão laminar como a principal responsável pela perda de solos férteis nas encostas em todo o mundo.

\section{Considerações finais}

O Cambissolo estudado apresenta pequenas variações em seus atributos físicos e químicos ao longo da encosta, na camada superficial de 0-20 cm, que demonstram baixa erodibilidade. No entanto, a erosão dos solos causada pela água é um problema muito mais complexo, pois envolve uma série de sub-processos e varia consideravelmente no tempo e espaço, de acordo com as interrelações entre os fatores controladores (FAVIS-MORTLOCK, 2012; GUERRA, 2016). Logo, as mudanças na cobertura vegetal, desencadeadas pelas atividades humanas, ao longo da encosta íngreme, coberta por Cambissolo, influenciam na resposta erosiva do solo, resultando em diferentes taxas de perda do mesmo.

Portanto, a adoção de medidas conservacionistas que busquem proteger, especialmente, a camada superficial do solo rica em MO, faz-se necessária para a continuidade, em bases sustentáveis, das atividades agrícolas desenvolvidas por pequenos produtores na área de amortecimento do PNSB. Para isto, no entanto, a intervenção de políticas públicas que visem fornecer assistência técnica aos produtores rurais é necessária.

\section{Agradecimentos}

Agradecemos a FAPERJ pelo auxílio financeiro, a parceria CAPES/EMBRAPA pela concessão de bolsa de pós-graduação e aos colegas do LAGESOLOS pela colaboração nos trabalhos de campo e de laboratório.

\section{Bibliografia}

ARAUJO, G. H. S.; ALMEIDA, J. R.; GUERRA, A. J. T. Gestão Ambiental de Áreas Degradadas. 2. ed. Rio de Janeiro: Ed. Bertrand Brasil, 2007.

BERTONI, J.; LOMBARDI NETO, F. Conservação do Solo. 9. ed. São Paulo: Ícone, 2014.

BRADY, N. C.; WEIL, R. R. The nature and properties of soils. 14. ed. Nova York: Prentice-Hall, 2008.

BRASIL. MINISTÉRIO DO MEIO AMBIENTE/IBAMA/DIREC. Plano de Manejo do Parque Nacional da Serra da Bocaina: Brasília: FEC/UNICAMP, 2002. 


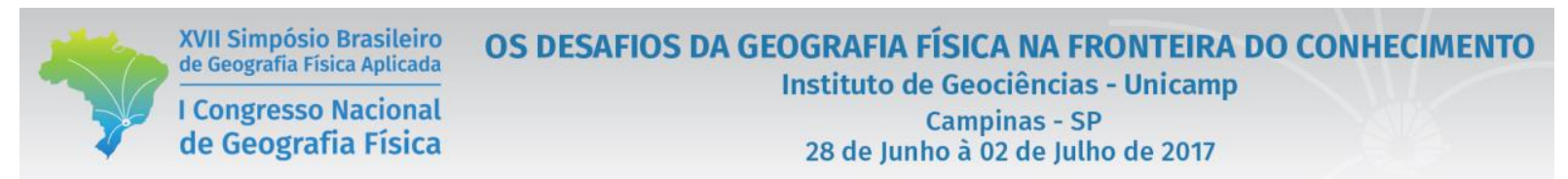

Lei Federal no 9.985, de 18 de julho de 2000 - Criação do Sistema Nacional de Unidades de Conservação (SNUC). 2000. Disponível em: <http://www.planalto.gov.br/ccivil_03/leis/19985.htm>. Acesso em: Agosto de 2015.

CARVALHO FILHO, A.; LUMBRERAS, J. F.; WITTERN, K. P.; LEMOS, A. L.; SANTOS, R. D.; CALDERANO FILHO, B.; CALDERANO, S. B.; OLIVEIRA, R. P.; AGLIO, M. L. D.; SOUZA, J. S.; CHAFFIN, C. E. Mapa de reconhecimento de baixa intensidade dos solos do estado do Rio de Janeiro. Rio de Janeiro: EMBRAPA Solos, 2003. Escala 1:250.000. Disponível em: 〈http://www.cnps.embrapa.br/solosbr/sigweb.html〉.

CASTRO FILHO, C.; MUZILLI, O.; PODANOSCHI, A. L. Estabilidade dos agregados e sua relação com o teor de carbono orgânico num Latossolo Roxo Distrófico, em função de sistemas de plantio, rotações de culturas e métodos de preparo das amostras. Revista Brasileira de Ciência do Solo, v. 22, p. 527-538, 1998.

CASTRO FILHO, C., LOURENÇO, A., D. E F. GUIMARÃES, M.; FONSECA, I. C. B. Aggregate stability under different soil management systems in a red latosol in the state of Parana, Brazil. Soil and Tillage Research. v. 65, n. 1, p. 45-51, 2002.

CUNHA, S. B.; GUERRA, A. J. T. Degradação Ambiental. In: GUERRA, A. J. T.; CUNHA, S. B. (Orgs.). Geomorfologia e Meio Ambiente. 10. ed. Rio de Janeiro: Ed. Bertrand Brasil, 2011. p. 337-379.

DE PLOEY, J.; POESEN, J. Aggregate stability, runoff generation and interrill erosion. In: RICHARDS, K. S.; ARNETT, R. R.; ELLIS, S. (Eds.). Geomorphology and Soils. London: George Allen, 1985.

EMBRAPA, Empresa Brasileira de Pesquisa Agropecuária. Manual de Métodos de Análise de Solo. 2. ed. Rio de Janeiro: Ministério da Agricultura e do Abastecimento, 1997.

FAVIS-MORTLOCK, D. T. Erosion by Water: Accelerated. In: JORGENSEN, S. E. (Ed.) Encyclopedia of Environmental Management. CRC Press, 2012.

GUERRA, A. J. T. Processos Erosivos nas Encostas. In: GUERRA, A. J. T.; CUNHA, S. B. (Orgs.). Geomorfologia: uma atualização de bases e conceitos. 12. ed. Rio de Janeiro: Bertrand Brasil, 2013. p. 149-209.

Degradação dos solos: conceitos e temas. In: GUERRA, A. J. T.; JORGE, M. C. O. (Orgs.). Degradação dos Solos no Brasil. Rio de Janeiro: Bertrand Brasil, 2014. p. 15-50.

Erosão dos Solos e Movimentos de Massa: Abordagens Geográficas. Curitiba: CRV Editora, 2016.

GUERRA, A. J. T.; FUllen, M. A.; JORGE, M. C. O.; BEZERRA, J. F. R. Slope Processes, Mass Movements and Soil Erosion: a review. Pedosphere. v. 27, p. 27-41, 2017.

GUERRA, A. J. T.; BEZERRA, J. F. R.; JORGE, M. C. O.; FULLEN, M. A. The geomorphology of Angra dos Reis and Paraty Municipalities, Southern Rio de Janeiro State. Revista Geonorte, v. 9, n. 1, p. 1-21, 2013.

ILEK, A.; KUCZA, J.; SZOSTEK, M. The effect of the bulk density and the decomposition index of organic matter on the water storage capacity of the surface layers of forest soils. Geoderma. v. 285, p. 27-34, 2017.

KEESSTRA, S.; PEREIRA, P.; NOVARA, A.; BREVIK, E. C.; MOLINA, C. A.; ALCÁNTARA, L. P.; JORDÁN, A.; CERDÀ, A. Effects of soil management techniques on soil water erosion in apricot orchards. Science of The Total Environment. v. 551-552, p. 357-366, 2016.

LEFF, E. Aventuras da Epistemologia Ambiental: da articulação das ciências ao diálogo de saberes. São Paulo: Cortez, 2012.

LEPSCH, I. F. 19 lições de pedologia. São Paulo: Oficina de Texto, 2011.

MAFRA, N. M. C. Erosão e Planificação de Uso do Solo. In: GUERRA, A. J. T.; SILVA, A. S.; BOTELHO, R. G. M. (Orgs.). Erosão e Conservação dos Solos: Conceitos, Temas e Aplicações. 8. ed. Rio de Janeiro: Bertrand Brasil, 2012. p. 301-322.

MORGAN, R. P. C. Soil Erosion and Conservation. 3. ed. England: Blackwell, 2005.

MÜLLER-NEDEBOCK, D.; CHAPLOT, V. Soil carbon losses by sheet erosion: a potentially critical contribution to the global carbon cycle. Earth Surface Processes and Landforms. v. 40, p. 1803-1813, 2015. 
OSMAN, K. T. Soil Degradation, Conservation and Remediation. Dordrecht: Spring, 2014.

PEREIRA, A. A.; THOMAZ, E. L. Parâmetros físicos do solo em diferentes sistemas de manejo convencional, município de Reserva - PR. Revista do Departamento de Geografia - USP. v. 30, p. 65-76, 2015.

PEREIRA, L. S.; RODRIGUES, A. M.; JORGE, M. C. O.; GUERRA, A. J. T.; FULLEN, M. A. Processos hidroerosivos em solos degradados em relevo de baixa declividade. Revista Brasileira de Geomorfologia. v. 17, n. 2, p. 299-316, 2016.

PIDWIRNY, M. Understanding Physical Geography. Kelowna: Our Planet Earth, 2014.

RIO DE JANEIRO. SECRETÁRIA ESTADUAL DO AMBIENTE. O Estado do Ambiente: indicadores ambientais do Rio de Janeiro. Rio de Janeiro: SEA/INEA, 2011.

TRICART, J. Ecodinâmica. Rio de Janeiro: IBGE, Diretoria Técnica, SUPREN, 1977.

WANG, B.; ZHENG, F.; ROMKENS, M. J. M.; DARBOUX, F. Soil erodibility for water erosion: a perspective and Chinese experiences. Geomorphology. v. 187, p. 1-10, 2013.

XU, M.; LI, Q.; WILSON, G. Degradation of soil physicochemical quality by ephemeral gully erosion on sloping cropland of the hilly Loess Plateau, China. Soil \& Tillage Research. v. 155, p. 9-18, 2016. 